\title{
PAINFUL MUSCULOSKELETAL DISEASES IN METABOLIC SYNDROME
}

\author{
Marcia Midori Shinzato ${ }^{1, \star}$, Pamela Judith Silva Constatin ${ }^{1}$, Franciely Bueno Wigineske ${ }^{1}$, Elias Silva de Medeiros $^{1}$ \\ 1.Universidade Federal da Grande Dourados, Dourados (MS), Brazil. \\ *Corresponding author: marciashinzato@ufgd.edu.br
}

\section{BACKGROUND}

Musculoskeletal diseases can worsen metabolic syndrome (MetS) as patients develop sedentary behaviors leading to loss of muscle which can damage other musculoskeletal structures. Therefore, we aimed to study musculoskeletal diseases in patients with MetS by comparing clinical and laboratory features between groups with and without MetS.

\section{MATERIALS AND METHODS}

This case-control study included 64 and 42 individuals with and without MetS, respectively, with similar age, and sex distribution recruited between June 2018 and September 2019. They underwent medical evaluation for the diagnosis of musculoskeletal disorders lasting more than 12 weeks and also to documented metabolic syndrome features. First univariate analysis was carried out for laboratory parameters, each musculoskeletal site and also for knee osteoarthritis, plantar fasciitis and fibromyalgia. Variables resulting significant or with marginal significance were selected for multivariate analysis by logistic regression. The ethics committee from UFGD approved the study (CAAE57333816.5.0000.5160) and all participants signed an informed consent for participation.

\section{RESULTS}

Individuals with MetS have higher frequency of chronic musculoskeletal pain $(73.44 \% \mathrm{vs} \mathrm{52.38 \% ,} \mathrm{p}=0.044)$. They have a significant higher frequency of pain localized in the knees (35.93\% vs 4.76\%, $p=0.0005)$, hips (12.5\% vs $0 \%, p=0.004)$ and ankles and feet (32.81\% vs. 7.14\%, $p=0.0044)$. The frequency of low back pain is also higher in persons with MetS (40.62\% vs. $21.43 \%, p=0.065)$. Clinical knee osteoarthritis was diagnosis in 16/64 (25\%) patient with MetS and in 1/42 (2.38\%) individuals without MetS, $p=0.002$. They also had a higher frequency of plantar fasciitis $(17.19 \%$ vs $2.38 \%, p=0.026)$ and fibromyalgia (20.31\% vs 4.76\%, $p=0.043$ ). Patients with MetS have also higher levels of uric acid (UA) (mean $6.03 \pm 1.80 \mathrm{mg} / \mathrm{dL}$ vs. $4.64 \pm 2.00 \mathrm{mg} / \mathrm{dL}$, respectively, $\mathrm{p}<0.0001$ ) and higher level of C-reactive protein (CRP), median 3.8 (interquartile interval $[|\mathrm{Q}|=2-8.35])$ vs 1.25 ( $\mathrm{IQI}=0.62-2.17), p<0.0001$. After inclusion of $\mathrm{BMl}$ categorized as $\geq$ and $<25 \mathrm{~kg} / \mathrm{m} 2$ in a logistic regression model, low back pain (odds ratio $[\mathrm{OR}]=16.80,95 \%$ confidence interval $[\mathrm{Cl}]=1.44-32.05, \mathrm{p}=0.015$ ), knee osteoarthritis (OR $=12.52$, $95 \% \mathrm{Cl}=1.05-148.9, \mathrm{p}=0.04), \mathrm{UA}(\mathrm{OR}=1.08,95 \% \mathrm{Cl}=1.37-3.09)$ and $\mathrm{CRP}(\mathrm{OR}=1.15,95 \% \mathrm{Cl}=1.02-1.31)$ remain significantly associated with MetS. There is no association of UA and CRP with any MSK diseases.

\section{CONCLUSION}

There is a higher frequency of chronic musculoskeletal pain in MetS especially in the weight bearing sites. Low back pain, knee osteoarthritis and plantar fasciitis were the most frequent specific MSK diseases. Low back pain and knee osteoarthritis, UA and CRP were associated with MetS after adjustment for overweight/obesity..

\section{ACKNOWLEDEGMENTS}

We would like to thank the staff of the University Hospital laboratory for collecting the sera and performing uric acid, C-reactive protein, and erythrocyte sedimentation rate assays. 